\title{
Development and Application of an Enzyme-linked Immunosorbent Assay for the Quantitation of Alternative Complement Pathway Activation in Human Serum
}

James T. Mayes, Robert D. Schreiber, and Neil R. Cooper Research Institute of Scripps Clinic, Department of Immunology, La Jolla, California 92037

bstract. We have developed a new, specific, and highly sensitive enzyme-linked immunosorbent assay (ELISA) which quantitates activation of the alternative pathway in human serum, plasma, or on the surface of activators. The ELISA detects the third component of complement $(\mathrm{C} 3 \mathrm{~b})$, proteolytic fragment of complement Factor $\mathrm{B}(\mathrm{Bb})$, and properdin $(\mathrm{P})$ complex or its derivative product, $C 3 b, P$. In the method, activator-plasma mixtures, plasma containing an activated alternative pathway, or other samples are added to the wells of microtitration plates precoated with antibody to $\mathrm{P}$. $\mathrm{C} 3 \mathrm{~b}, \mathrm{Bb}, \mathrm{P}$ or $\mathrm{C} 3 \mathrm{~b}, \mathrm{P}$ complexes which become bound are quantitated by subsequently added, enzyme-labeled, anti-C3. The resulting hydrolysis of the chromogenic substrate is expressed as nanograms of $\mathrm{C} 3 \mathrm{~b}$ by reference to a $\mathrm{C} 3$ standard curve. In addition to absolute specificity for activation of the pathway because of the nature of the complex detected by the assay, the ELISA is highly sensitive and able to reproducibly detect $10-20 \mathrm{ng} / \mathrm{ml}$ of $\mathrm{C} 3 \mathrm{~b}, \mathrm{P}$ complexes in serum. This value corresponds to $0.0015 \%$ of the $\mathrm{C} 3$ in serum. In a series of studies to validate the parameters of the ELISA, reactivity was found to be dependent on the presence of alternative pathway proteins, the functional integrity of the pathway, and on the presence of magnesium. Sheep erythrocytes were converted to activators by treatment with neuraminidase. By using a variety of activators, the kinetics of activation and the numbers of bound $\mathrm{C} 3 \mathrm{~b}$ molecules quantitated by the ELISA

This is publication no. 2878 from Scripps Clinic and Research Foundation, Department of Immunology.

Address all reprint requests to Dr. Cooper.

Received for publication 13 December 1983 and in revised form 1 September 1983.

J. Clin. Invest.

(c) The American Society for Clinical Investigation, Inc.

$0021-9738 / 84 / 01 / 0160 / 11 \$ 1.00$

Volume 73, January 1984, 160-170 were very similar to those measured by $\mathrm{C} 3 \mathrm{~b}$ deposition. The ELISA also detected identical activation kinetics when MgEGTA-serum and a mixture of the purified alternative pathway proteins were used as sources of the pathway. ELISA reaction kinetics also correlated with the restriction index, a measure of alternative pathway-activating ability. These studies cumulatively validate the ELISA as a direct and quantitative assay for alternative pathway activation.

The sensitivity of the ELISA has permitted its use to detect direct alternative pathway activation by several viruses. The ELISA has also shown that certain classical pathway activators trigger the amplification loop of the alternative pathway while others do not. In addition, stable ELISA reactive complexes appeared in the supernatant of mixtures of serum with certain, but not other activators.

The ability of the ELISA to detect activation which has already occurred and the stability of the reactive complexes permits studies of clinical sera. Normal human sera (20) contained low levels $(5-20 \mathrm{ng} / \mathrm{ml})$ of ELISAreactive complexes. A proportion of sera from individuals with the adult respiratory distress syndrome (9 of 10), typhoid fever ( 8 of 10$)$, malaria ( 3 of 5), gram-negative sepsis ( 9 of 47), acute trauma and shock (6 of 25 ), and systemic lupus erythematosus ( 3 of 29 ) showed elevated levels of complexes reactive in the alternative pathway ELISA. In contrast, nine sera from patients with circulating $\mathrm{C} 3$ nephritic factor were not reactive in the ELISA.

\section{Introduction}

The properdin $(\mathrm{P})^{1}$ system, also known as the alternative complement pathway, was originally characterized as a system of natural immunity which did not require antibody and which

1. Abbreviations used in this paper: ARDS, adult respiratory distress syndrome; Bb, proteolytic fragment of complement Factor B; C3, third component of complement; $\mathrm{C} 3 \mathrm{~b}$, major cleavage fragment of $\mathrm{C} 3$; $\mathrm{C} 3 \mathrm{NeF}$, C3 nephritic factor; C5, fifth component of complement; $E_{R}$, rabbit 
functioned in host defense against various pathogens including bacteria, viruses, and protozoa (1). The alternative complement pathway has been implicated in the pathogenesis or symptomatology of a broad spectrum of human diseases and pathologic conditions. These include: infections with gram-positive and gram-negative bacteria $(2,3)$, viruses $(4,5)$, parasites $(6,7)$, and fungi (8); various dermatologic (9), renal (10), and hematologic (11-13) diseases; adult respiratory distress syndrome (ARDS) associated with gram-negative septicemia, trauma, and burns (14-18); contact with dialysis membranes such as in hemodialysis (19) and cardiac bypass surgery (20); and miscellaneous conditions (21). In vitro studies indicate that a number of gramnegative bacteria and bacterial products (22), virus-infected cells (23), viruses (24), protozoa (25), fungi (26), burned, damaged, and injured cells (27), and other substances of biomedical importance (28) have the ability to activate the alternative pathway in human serum.

Multiple studies during the past few years have identified the components of the alternative complement pathway and have elucidated their reaction mechanisms $(29,30)$. Activation of this pathway leads to the assembly of a multicomponent enzyme on the surface of the activator. This enzyme, third component of complement $(\mathrm{C} 3 \mathrm{~b})$, proteolytic fragment of complement Factor $\mathrm{B}(\mathrm{Bb}), \mathrm{P}$, is able to cleave fifth component of complement (C5) and initiate the membranolytic portion of the complement reaction sequence. The methods presently available to assess and quantitate alternative pathway function and activation are limited in number and utility and most are available only in laboratories engaged in research on the alternative pathway.

This paper describes an enzyme-linked immunosorbent assay (ELISA) which can quantitate the $\mathrm{C} 3 \mathrm{~b}, \mathrm{Bb}, \mathrm{P}$ complex or its derivative product, $\mathrm{C} 3 \mathrm{~b}, \mathrm{P}$ on the surface of activators or in serum or plasma. This method thus directly measures activation of the alternative complement pathway. In addition to absolute specificity, the ELISA is extremely sensitive and capable of quantitating specific activation of $0.0015 \%$ of the $C 3$ in plasma. The studies presented here not only validate the ELISA and quantitate its parameters, but also illustrate its utility for detailed analysis of activation of the alternative pathway by isolated viruses, virus-infected cells, and bacteria. In addition, moderate to marked ELISA reactivity was observed in sera from those patients with diseases in which alternative pathway activation would be expected.

\section{Methods}

Reagents and buffers. Tween 20 , fraction $\mathrm{V}$ bovine serum albumin (BSA), $p$-nitrophenyl phosphate, type VII alkaline phosphatase from

erythrocytes; $E_{S}$, sheep erythrocytes; $E A$, antibody-coated erythrocyte; EDTA-NHS, normal human serum containing 20 mM EDTA; ELISA, enzyme-linked immunosorbent assay; MgEGTA-NHS, normal human serum containing $2.5 \mathrm{mM} \mathrm{Mg}$ and $10 \mathrm{mM}$ EGTA; NHS, normal human serum; P, properdin; PAP, purified alternative pathway proteins; SLE, systemic lupus erythematosus; VBS, veronal-buffered saline, $\mathrm{VBS}^{++}$, veronal-buffered saline with $\mathrm{Ca}^{+2}$ and $\mathrm{Mg}^{+2}$. calf mucosa (Sigma Chemical Co., St. Louis, MO), diethanolamine (Eastman Kodak Co., Rochester, NY), neuraminidase (Gibco Laboratories, Grand Island, NY), tetanus toxoid (Lederle Laboratories, Pearl River, NY), heparin, Lipo-Hepin U.S.P. (1000 U/ml, Riker Laboratories, Inc., Northridge, CA) and calf thymus DNA (Worthington Laboratories, Freehold, NJ), were purchased from the referenced manufacturers. Veronal-buffered saline (VBS) and veronal-buffered saline with $\mathrm{Ca}^{+2}$ and $\mathrm{Mg}^{+2}\left(\mathrm{VBS}^{++}\right)$were prepared as described (31). Phosphate-buffered saline (PBS) contained $12 \mathrm{mM}$ phosphate and $150 \mathrm{mM} \mathrm{NaCl}, \mathrm{pH} 7.4$.

Human sera. Venous blood from normal individuals was clotted in glass tubes for an hour at room temperature and centrifuged; the sera were stored at $-70^{\circ} \mathrm{C}$. Sera from patients with a diagnosis of ARDS were generous gifts of Dr. Charles Cochrane of this Institute. Sera from patients with a diagnosis of typhoid fever were obtained from the United States Naval Medical Research Unit No. 2, Jakarta Detachment. Sera from patients with various diseases were kindly supplied by Drs. John Curd, Carolyn Mold, Robert Reid, and Curtis Wilson.

Complement-deficient and depleted sera. C2-deficient and C7-deficient human sera were from individuals with genetic deficiency of the proteins. C2-, C3-, B-, and C4-depleted sera were made by passing serum samples through affinity columns bearing the IgG fraction of the appropriate monospecific antisera in $10 \mathrm{mM}$ EDTA. Absence of the appropriate component was determined by Ouchterlony analyses and specific functional assays. Only sera which could be substantially reconstituted $(>80 \%)$ in functional activity by the addition of physiological levels of the missing protein in purified form (together with $\mathrm{Clq}$ ) were used.

Complement proteins and cellular intermediates. C3 (32), B (33), D (34), cofactor of Factor I (H) (35), and inactivator of C3 (I) (35) were purified to homogeneity from human serum by the published methods. C3b (36), C3b dimers, C3bi, C3c, C3d (37), Clq, and nephritic factor $(\mathrm{C} 3 \mathrm{NeF})(38,39)$ were prepared or purified as described in References. $P$ was purified by a modification of the method of Medicus et al. (40). Briefly, EDTA was added to normal serum to a concentration of $5 \mathrm{mM}$ and the serum was passed over BioRex 70 (Bio-Rad Laboratories, Richmond, CA), as previously described for Clq purification (38). Fall-through fractions containing $P$ were pooled and dialyzed into $20 \mathrm{mM}$ Tris- $\mathrm{HCl}$ containing $30 \mathrm{mM} \mathrm{NaCl}, \mathrm{pH} 8.5, K=3.9$. The remainder of the procedure was as published (40). Activated $P$ was generated by repetitive freezethawing of the preparation (40). C3 was radiolabeled with ${ }^{125}$ I by the lactoperoxidase procedure (Enzymo beads, Bio-Rad Laboratories) to a level of $1 \mu \mathrm{Ci} / \mu \mathrm{g}$ and used within a week of radiolabeling. Mixtures of the purified alternative pathway proteins $\mathrm{C} 3, \mathrm{~B}, \mathrm{D}, \mathrm{H}, \mathrm{I}$, and $\mathrm{P}$ (PAP) at physiological concentrations were prepared in VBS and used as previously described (41). Sheep erythrocytes $\left(E_{s}\right)$ bearing only C3b were generated with purified $\mathrm{C} 3$ and Factors $\mathrm{B}, \mathrm{D}$, and $\mathrm{C} 3 \mathrm{NeF}$ as previously described (42). The cells carried 50-100,000 C3b molecules on their surface.

Activator and nonactivator particles. $\mathrm{E}_{\mathrm{s}}$, which was purchased from Colorado Serum Co. (Denver, $C O$ ), and rabbit erythrocyte $\left(E_{R}\right)$, from normal laboratory rabbits, were washed three times in $\mathrm{VBS}^{++}$and resuspended at various concentrations in the same buffer for use. Antibodycoated erythrocyte (EA)C4b3b were prepared by incubating $300 \mu \mathrm{g}$ of $\mathrm{C} 3$ with $5 \times 10^{8} \mathrm{EACl} 142$ for $20 \mathrm{~min}$ at $37^{\circ} \mathrm{C}$. The cells were then washed twice in VBS containing $10 \mathrm{mM}$ EDTA and incubated for $3 \mathrm{~h}$ at $37^{\circ} \mathrm{C}$ to allow decay of $\mathrm{C} 2$. The cells were washed and resuspended at $1 \times 10^{8} /$ $\mathrm{ml}$ in VBS for use. The presence of $\mathrm{C} 3 \mathrm{~b}$ on the cells was confirmed by hemagglutination with affinity-purified anti-C3.

Raji cells from a Burkitt's lymphoma cell line were grown in RPMI 1640 supplemented with $10 \%$ fetal calf serum (Rehatuin, Kankakee, IL), $2 \mathrm{mM}$ glutamine (Gibco Laboratories), penicillin, and streptomycin. 
The cells were harvested at a concentration of $1 \times 10^{6} / \mathrm{ml}$, washed two times in PBS, and viability was ascertained to be $>95 \%$ by trypan blue exclusion before use.

Gram-negative bacteria included serum sensitive Escherichia coli 04 and serum resistant Klebsiella pneumonia laboratory strains. The bacteria were grown in trypticase soy broth (Becton-Dixon Co., Cockeysville, MD) and harvested at a concentration of $1 \times 10^{9} / \mathrm{ml}$, as determined by nephelometry and colony-forming unit determination. The organisms were washed three times in $\mathrm{VBS}^{++}$and heat killed for $1 \mathrm{~h}$ at $80^{\circ} \mathrm{C}$ before use.

Zymosan A (Sigma Chemical Co.) was boiled for $2 \mathrm{~h}$ in $0.15 \mathrm{M}$ $\mathrm{NaCl}$. The particles were washed in $\mathrm{VBS}^{++}$and resuspended to $\sim 50$ $\mathrm{mg} / \mathrm{ml}$ and frozen at $-70^{\circ} \mathrm{C}$ in aliquots until use.

Human tetanus-antitetanus immune complexes were generated as previously described (43). The final suspension contained $1-2 \mathrm{mg} / \mathrm{ml}$ of protein by Folin-Lowry determination (44).

Epstein-Barr virus (45), influenza WS/33 (46), and Moloney leukemia virus (47) were prepared in this laboratory by previously published procedures.

Affinity purification of anti-C3 and anti-P for use in the ELISA. 10 $\mathrm{mg}$ of $\mathrm{C} 3$ and $1 \mathrm{mg}$ of $\mathrm{P}$ were separately coupled to $1 \mathrm{~g}$ of $\mathrm{CNBr}$ activated Sepharose 4B (Pharmacia Fine Chemicals, Piscataway, NJ) using the instructions of the manufacturer. Monospecific goat anti-C3 and rabbit anti-P sera were precipitated with $33 \%$ ammonium sulfate. The precipitates, after dissolution and dialysis into VBS, were passed through the appropriate $\mathrm{C} 3$ or $\mathrm{P}$ columns in VBS. After extensive washing with $3 \mathrm{M} \mathrm{NaCl}$ in VBS, the columns were stripped with $0.2 \mathrm{M}$ glycine$\mathrm{HCl}, \mathrm{pH}$ 2.2. The protein-containing fractions were pooled, immediately neutralized, and dialyzed into PBS. The affinity-purified antibodies were frozen at $-70^{\circ} \mathrm{C}$ until use.

Alkaline phosphatase-labeling of antibodies. Alkaline phosphatase (Sigma type VII) was conjugated to the above described, affinity-purified anti-C3 by the method of Voller (48). The dilution of the enzymelabeled antibody to $\mathrm{C} 3$ to be used was determined by adding 1:100 to 1:5,000 dilutions to wells of a microtitration plate (Linbro Sterile/Titertek, Linbro Chemical Co., Hamden, CT) previously coated with affinitypurified IgG antibody to $C 3(5 \mu \mathrm{g} / \mathrm{ml})$ followed by a 1:10,000 dilution of serum (see below). The ELISA was then performed as described below and the highest conjugate dilution that gives an optical density reading of just under 2.0 at $405 \mathrm{~nm}$ was determined. This dilution was generally 1:750.

ELISA. The assay was a modification of the standard method of Voller (48). Microtitration plates were coated with $0.1 \mathrm{ml}$ volumes of the affinity-purified anti-P antibody at a concentration of $5 \mu \mathrm{g} / \mathrm{ml}$ in PBS by overnight dessication at room temperature. Next, $0.2 \mathrm{ml}$ of PBS:0.5\% BSA were added and the plates incubated for $2 \mathrm{~h}$ at $37^{\circ} \mathrm{C}$ in a humid incubator. After removal of this blocking solution, the plates were washed once with PBS containing 0.05\% Tween 20 (PBS-Tween).

Dilutions of samples to be tested for ELISA reactivity in PBS-Tween$10 \mathrm{mM}$ EDTA-0.25\% BSA (PBS-Tween-EDTA-BSA) were placed in $0.1 \mathrm{ml}$ volumes, in triplicate, into the coated plates. After rocking for $1 \mathrm{~h}$ at room temperature, the plates were washed three times with PBSTween. Next, $0.1 \mathrm{ml}$ of alkaline phosphatase-conjugated antibody to C3 diluted in PBS-Tween-EDTA-BSA was added. The plates were again rocked for $1 \mathrm{~h}$ at room temperature, and washed three times with PBSTween after which $0.1 \mathrm{ml}$ of $p$-nitrophenyl phosphate at a concentration of $1 \mathrm{mg} / \mathrm{ml}$ in diethanolamine buffer (48) was dispensed into the wells. The plates were read at $405 \mathrm{~nm}$ after varying times (usually 10-60 min) in a Titertek multiscan photometer (Flow Laboratories, McLean, VA), which was standardized to wells containing all reactants except the experimental samples. Since color development was linear with time to an optical density of $\sim 2.0$, the optical density change per minute was calculated. Where appropriate, these values were converted to nanograms per milliliter of $\mathrm{C} 3$ by comparison with the standard curve. In all studies, another control included uncoated wells which received the reaction mixtures, conjugated antibody, and substrate. Where appropriate, these values were subtracted from experimental wells.

C3 Standard curve and conversion of ELISA values to nanograms of $C 3 b$. A standard curve was included on each plate. Twofold dilutions of purified human $\mathrm{C} 3(10-300 \mathrm{ng} / \mathrm{ml})$ in $0.1 \mathrm{ml}$ volumes in PBS-TweenEDTA-BSA were added in duplicate to wells that had been precoated with anti-C3. Precoating was accomplished by dessication of $0.1 \mathrm{ml}$ volumes of a $5 \mu \mathrm{g} / \mathrm{ml}$ solution of anti-C3 in PBS overnight at room temperature. Enzyme-labeled anti-C3 and subsequently substrate were added exactly as described in the section above. A linear relationship between optical density at $405 \mathrm{~nm}$ and $\mathrm{C} 3$ concentration prevailed to a C3 concentration of $300-500 \mathrm{ng} / \mathrm{ml}$.

General procedure for testing samples for the ELISA. Normal human serum (NHS), NHS containing $2.5 \mathrm{mM} \mathrm{Mg}$ and $10 \mathrm{mM}$ EGTA (MgEGTA-NHS), complement component-deficient or depleted sera, or the PAP (in VBS) were incubated, generally in undiluted form, but occasionally in a dilution as specified in the text with an equal volume of a suspension of the activator in VBS. Generally, $50 \mu \mathrm{l}$ volumes were used. Unless otherwise specified, $E_{s}, E_{R}$, neuraminidase-treated $E_{s}$, and Raji cells were used at $1 \times 10^{8} / \mathrm{ml} ; E$. coli $\mathrm{O} 4$ and $K$. pneumoniae at $1 \times 10^{9} / \mathrm{ml}$; zymosan at $2.5 \mathrm{mg} / \mathrm{ml}$; human immune complexes at 2.0 $\mathrm{mg} / \mathrm{ml}$; heparin at $500 \mathrm{U} / \mathrm{ml}$; DNA at $20 \mu \mathrm{g} / \mathrm{ml}$; influenza virus at $1 \times 10^{10} \mathrm{particles} / \mathrm{ml}$; Epstein-Barr virus at $1 \times 10^{9} \mathrm{particles} / \mathrm{ml}$; and Moloney leukemia virus at $2 \mathrm{mg} / \mathrm{ml}$ protein. The mixtures were incubated at $37^{\circ} \mathrm{C}$ and samples were taken at intervals. When dose-response rather than kinetic studies were carried out, equal volumes of MgEGTA-NHS and particles (from $1 \times 10^{6} / \mathrm{ml}$ to $1 \times 10^{9} / \mathrm{ml}$ ) were incubated together for $40 \mathrm{~min}$ at $37^{\circ} \mathrm{C}$. The samples of the reaction mixtures were diluted in PBS-Tween-EDTA-BSA and triplicate $0.1 \mathrm{ml}$ samples were assayed in the ELISA. The dilution used for each activator was dependent on the potency or "strength" of the activator; for weak activators and thus bearing small amounts of $P$ and $C 3 b$, a 1:10 or 1:20 dilution was utilized, while for "strong" activators, a higher dilution such as 1:50 or 1:100 was used. Clinical sera were diluted 1:10 for assay.

Slight modifications were employed to assay the activation complex on the surface of the activator. These included washing after incubation of the activator with serum (erythrocytes) or centrifugation of $20-\mu 1$ aliquots of the reaction mixtures through a $300-\mu 1$ layer of $20 \%$ sucrose in PBS with $10 \mathrm{mM}$ EDTA (bacteria, zymosan). The pellets were resuspended in smaller (i.e., $0.3-0.5 \mathrm{ml}$ ) or larger (i.e., $1.0-1.5 \mathrm{ml}$ ) volumes of PBS-Tween-EDTA-BSA for weak or strong activators, respectively, and triplicate $0.1 \mathrm{ml}$ samples were analyzed in the ELISA.

In some studies, supernatants of the activation mixtures were also tested. In these instances, samples of the reaction mixtures were diluted in PBS-Tween-EDTA-BSA and then centrifuged in the Beckman microfuge (Beckman Instruments, Inc., Fullerton, CA). Triplicate $0.1 \mathrm{ml}$ samples of the supernatants were tested in the ELISA.

Binding of $P$ to $C 3 b$-coated erythrocytes. Equal volumes of increasing concentrations of activated $P$ were incubated with EC3b $\left(2.5 \times 10^{6} / \mathrm{ml}\right.$ in $\mathrm{VBS}^{++}$) for $15 \mathrm{~min}$ at $37^{\circ} \mathrm{C}$. The cells were then washed, resuspended in VBS, and triplicate $0.1-\mathrm{ml}$ samples were assayed in the ELISA.

Radiolabeled C3 deposition on activators. MgEGTA-NHS, to which radiolabeled $\mathrm{C} 3$ had been added, was incubated at $37^{\circ} \mathrm{C}$ in equal volumes with suspension of activators. At intervals, 20- $\mu$ l samples were layered over $300 \mu \mathrm{l}$ of $20 \%$ sucrose solution in VBS containing $10 \mathrm{mM}$ EDTA. After centrifugation for $5 \mathrm{~min}$ in a Beckman microfuge, the tips of the tubes were amputated and the pellets and supernates and remainder of 
the tube counted in a Packard auto-gamma spectrometer (Packard Instrument Co., Inc., Downers Grove, IL). The radioactivity values were converted to molecules of $\mathrm{C} 3$ per activator particle by knowledge of the total $\mathrm{C} 3$ concentration of the radiolabeled $\mathrm{C} 3$ mixture (determined by Mancini analyses) and the specific radioactivity of the mixture. Duplicate samples of the same reaction mixtures were similarly centrifuged and the pellets analyzed in the ELISA as described above.

\section{Results}

C3 Standard Curve. As shown in Fig. 1, the C3 standard curve yielded a linear relationship between the optical density and the C3 concentration to a level of $300-500 \mathrm{ng} / \mathrm{ml}$. The lower limit of detection of C3 (Fig. 1) was 10-20 ng/ml (1-2 $\mathrm{ng} /$ well), a level which yielded an optical density of $\sim 0.100$ after an hour of incubation. This amount of $\mathrm{C} 3$ corresponds approximately to the amount in a $10^{-5}$ dilution of human serum $(\sim 16 \mathrm{ng} / \mathrm{ml})$. Different C3 preparations yielded very similar standard curves (Fig. 1). In other studies, serum samples of known $\mathrm{C} 3$ content yielded the same standard curve as purified C3 (not shown). The repetitive standard curves, which were included on each plate and encompassed several preparations of affinity-purified anti-P and enzyme-conjugated anti-C3, yielded only minor variations as noted in the next section. In contrast to many ELISA systems, direct coupling of the antigen to the plate yielded far lower sensitivity (Fig. 1).

The ability of the anti-C 3 employed in these studies to detect various forms and fragments of $\mathrm{C} 3$ was examined. For these experiments, purified C3, C3b, C3b dimers, C3bi, C3c, and C3d were substituted for $\mathrm{C} 3$ in the standard curve determination. The antibody detected $\mathrm{C} 3, \mathrm{C} 3 \mathrm{~b}$, and $\mathrm{C} 3 \mathrm{~b}$ dimers with very similar dose-response characteristics. Slightly less reactivity was observed with $\mathrm{C} 3 \mathrm{bi}$ and $\mathrm{C} 3 \mathrm{c}(50-70 \%$ of that produced by $\mathrm{C} 3$ ) while the antibody detected C3d poorly $(\sim 10 \%$ of the optical density given by the same amount of $\mathrm{C} 3$ ).

Validity of alternative pathway measurements by the ELISA. A number of different types of studies were carried out to ascertain the requirements for the ELISA and to show that it specifically measured $\mathrm{C} 3 \mathrm{~b}$ and $\mathrm{P}$ deposition mediated by activation of the alternative pathway. To show a requirement for both $\mathrm{C} 3 \mathrm{~b}$ and $\mathrm{P}$ on the same particle for reactivity in the ELISA,

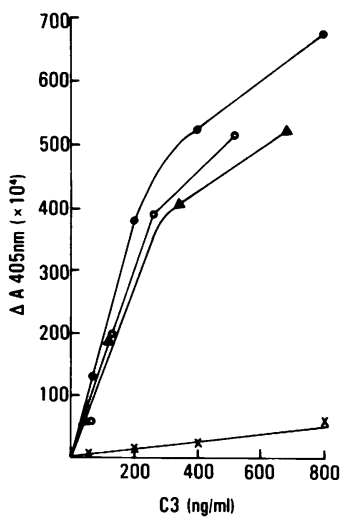

Figure 1. C3 standard curves. Purified human $\mathrm{C} 3$ was diluted from 50 to $800 \mathrm{ng} / \mathrm{ml}$ and placed into wells that had been precoated with anti-C $3(\bullet$, $\mathrm{O}, \mathbf{\Delta})$ alternatively; $\mathrm{C} 3$ was dessicated in uncoated wells $(X)$. After washing, enzyme-labeled immunospecific antiC3 was added and subsequently substrate. The symbols, $(\bullet),(O),(\Delta)$, denote three different $\mathrm{C} 3$ preparations; $(\mathbf{\Delta})$ and $(X)$ represent the same preparation.

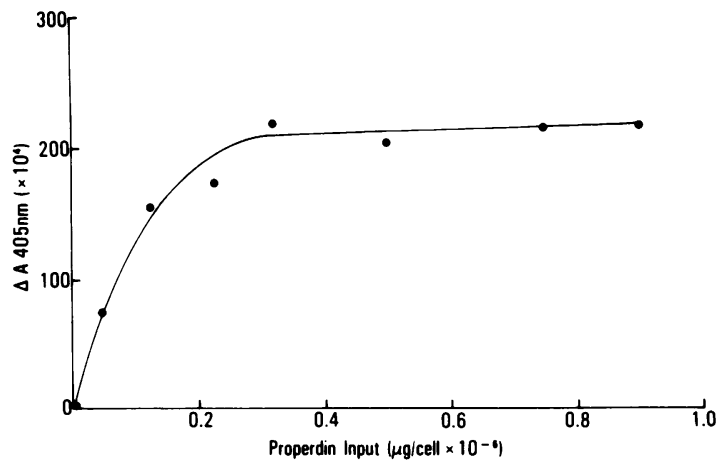

Figure 2. Requirements for $\mathrm{C} 3 \mathrm{~b}$ and $\mathrm{P}$ on the same particle for reactivity in the ELISA. Varying amounts of activated $P$ were incubated with EC3b. After washing, the cells were examined for ELISA reactivity.

$\mathrm{E}_{\mathrm{s}}$-bearing $\mathrm{C} 3 \mathrm{~b}$ were reacted with varying amounts of activated $P$. After washing, the cells were examined in the ELISA. As shown in Fig. 2, reactivity in the ELISA correlated with the amount of activated $P$ added to the EC3b cells up to a plateau of reactivity at which point the cells are saturated with $P$.

Requirements for the proteins of the alternative pathway were also ascertained by adding an alternative pathway activator, $E$. coli $\mathrm{O} 4$, to normal serum, to serum depleted of $\mathrm{C} 3$, to serum depleted of $\mathrm{C} 3$ and reconstituted with physiological levels of purified C3, to serum depleted of Factor B, and to serum depleted of Factor B and reconstituted with physiological levels of purified B. After incubation, the reaction mixtures were diluted and examined in the ELISA. $E$. coli added with serum depleted of C3 or Factor B failed to react in the ELISA (Fig. 3). Reactivity was, however, regained after reconstitution of the missing component.

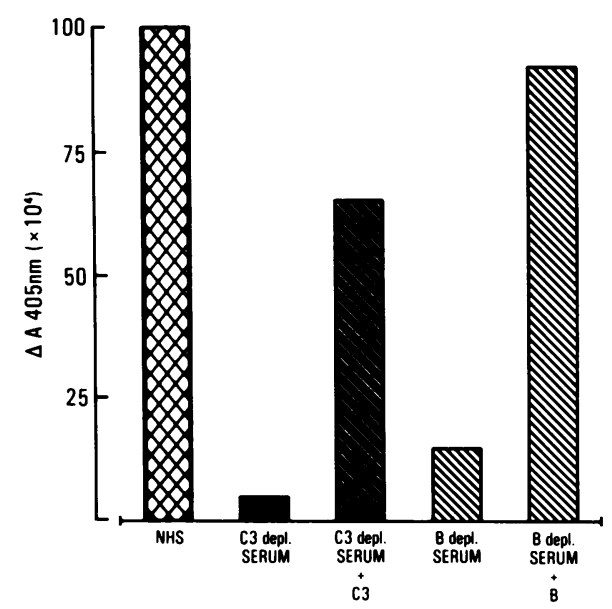

Figure 3. Requirements for C3 and Factor B for ELISA reactivity. $E$. coli $\mathrm{O} 4$ were incubated with normal serum, C3-depleted serum, reconstituted C3-depleted serum, Factor B-depleted serum, and reconstituted Factor B-depleted serum. The reaction mixtures were then diluted and aliquots examined for reactivity in the ELISA. 
In other studies, preneutralization of the anti-C 3 conjugate or the anti-P coated plates with an excess of purified $\mathrm{C} 3$ or native $P$ (EDTA serum), respectively, abrogated ELISA reactivity. Also, a serum-activator reaction mixture $(E$. coli $\mathrm{O} 4)$ preincubated with an excess of anti-P before addition to the microtiter wells did not react in the ELISA (not shown).

The next series of studies were done to determine whether the integrity of the alternative activation pathway was required for reactivity in the ELISA. $E_{R}$ and zymosan were reacted with C2-deficient serum, MgEGTA-NHS, or normal human serum containing $20 \mathrm{mM}$ EDTA (EDTA-NHS). As shown in Fig. 4, normal serum, C2-deficient serum, and MgEGTA-NHS (thus lacking calcium required for the classical pathway) supported full ELISA reactivity with both activators, whereas EDTA-NHS (lacking also magnesium, needed for both pathways) did not. In comparable studies, C4-depleted serum and MgEGTA-NHS supported full reactivity with $\mathrm{E}_{\mathrm{R}}$ and with $E$. coli $\mathrm{K} .12$ (not shown). Similarly, C2-deficient serum and normal serum yielded comparable ELISA values after reaction with zymosan. EDTA invariably abrogated ELISA reactivity. $E_{s}$, a nonactivator, failed to engender ELISA reactivity after incubation in serum.

In another approach, the effect of treatment of $E_{s}$ with neuraminidase, a procedure known to convert $E_{s}$ into alternative pathway activators (42), was examined. Untreated and neuraminidase-treated $E_{s}$ were incubated with MgEGTA-NHS and periodic samples were layered over cushions of sucrose and centrifuged. The $\mathrm{E}_{\mathrm{s}}$ pellets were examined for ELISA reactivity. The optical densities in the ELISA were converted to C3b molecules per cell by reference to the $\mathrm{C} 3$ standard curve. As shown in Fig. 5, neuraminidase treatment rendered $E_{s}$ reactive in the ELISA. Maximal C3b binding was observed after $15 \mathrm{~min}$ of incubation of the neuraminidase-treated $\mathrm{E}_{\mathrm{s}}$ with MgEGTA-NHS

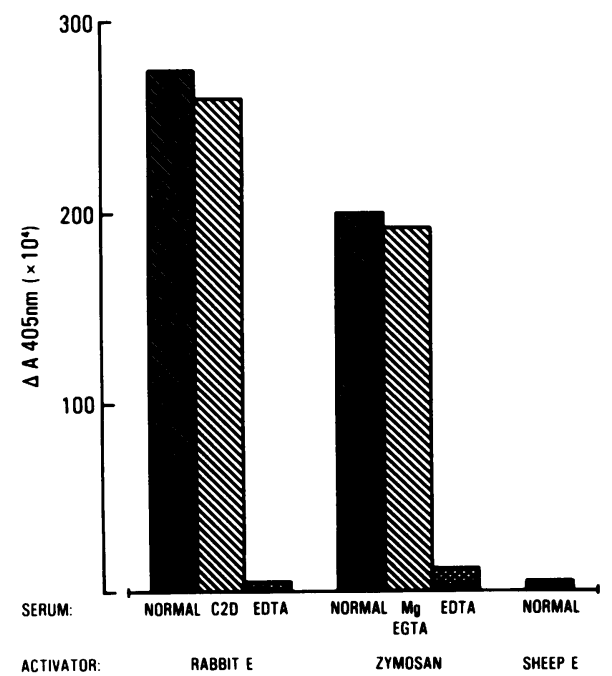

Figure 4. Requirements for the alternative activation pathway for ELISA reactivity. $E_{R}$, zymosan, or $E_{s}$ were incubated with normal serum, C2-deficient human serum, MgEGTA-NHS, or with EDTANHS. The mixtures were then diluted and examined in the ELISA.

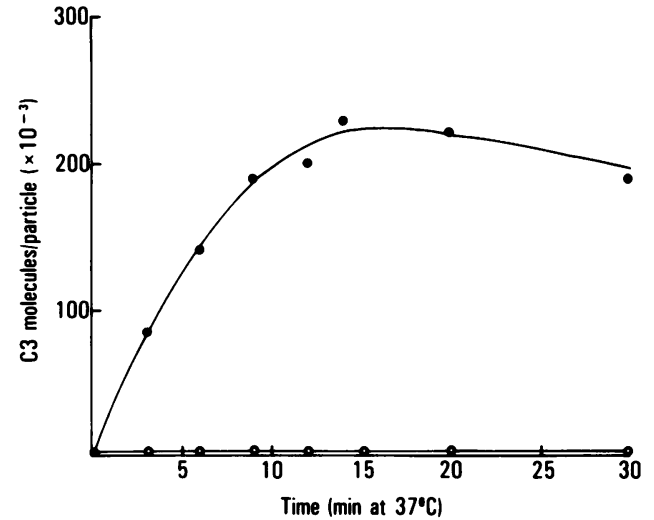

Figure 5. Conversion of $\mathrm{E}_{\mathrm{s}}$ into alternative pathway activators by treatment with neuraminidase. $E_{s}(O)$ and neuraminidase-treated $E_{s}$ (O) were incubated with MgEGTA-NHS and samples taken at intervals centrifuged through a cushion of sucrose. The cell pellets were resuspended and examined in the ELISA. The optical densities obtained were converted into bound C3b molecules per cell by reference to the $\mathrm{C} 3$ standard curve.

(Fig. 5). The treated $E_{s}$ were also observed to lyse in MgEGTANHS, confirming the conversion of the cells into alternative pathway activators.

Variability of the values between plates coated and tested on different days and assayed over a period of time was modest. Optical density variations for given values of $\mathrm{C} 3$ were generally less than $\pm 20 \%$. Statistical analysis of four standard curves performed at different times on different plates yielded a SE of the slope of 0.0965 . The correlation coefficient between the curves was 0.982 with a SE of the correlation coefficient of 0.0935 . Relatively little variation was observed in repetitive assays of activator serum mixtures. For example, 36 determinations with zymosan-treated serum on three different plates coated at different times yielded a maximum single value standard deviation, expressed as a percent of the mean of $25 \%$. Calculation of the distribution of variance using a two-tailed $\times 2$ analysis showed that 1 SD encompassed values lying between 5 and $13 \%$ of the mean (95\% confidence level).

Comparison of the ELISA with measurements of radiolabeled $C 3 b$ deposition on the activator. Two alternative pathway activators, $\mathrm{E}_{\mathrm{R}}$ and $K$. pneumoniae, and a nonactivator, $\mathrm{E}_{\mathrm{s}}$, were incubated with MgEGTA-NHS containing radiolabeled C3. Replicate samples of the reaction mixtures were taken at intervals, layered over cushions of sucrose, centrifuged, and the pellets examined for ELISA reactivity and for radiolabeled C3b binding. Values were expressed as $\mathrm{C} 3 \mathrm{~b}$ molecules per particle. As indicated in Fig. 6, measurements of alternative pathway activation by the ELISA and by radiolabeled C3b deposition exhibited parallel kinetic behavior. The numbers of bound $\mathrm{C} 3 \mathrm{~b}$ molecules per particle measured with the two approaches were similar. Both methods also gave comparable parallel results with other activators including several gram-negative bacteria and neuraminidase-treated $E_{s}$ (not shown). $E_{s}$ were nonreactive (Fig. 6). 


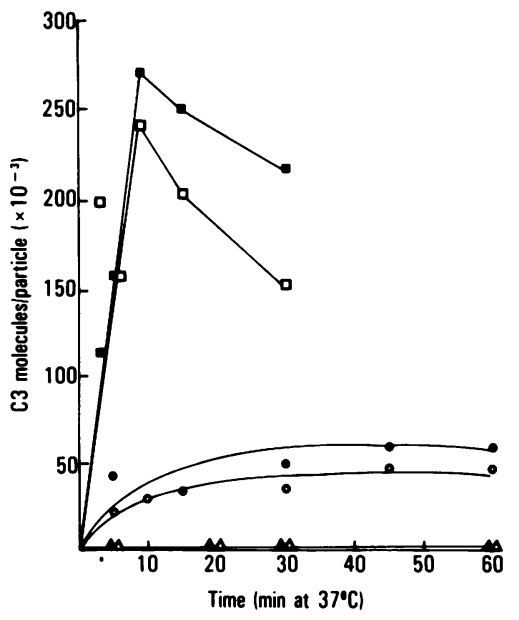

Figure 6. Comparison of the ELISA with measurements of radiolabeled $\mathrm{C} 3 \mathrm{~b}$ deposition. $\mathrm{E}_{\mathrm{R}}, K$. pneumoniae, and $\mathrm{E}_{\mathrm{s}}$ were incubated with MgEGTA-NHS containing radiolabeled C3. Samples taken at intervals were layered over sucrose cushions and centrifuged, and the pellets were assayed for radioactivity, and after resuspension, by the ELISA. Values were converted to $\mathrm{C} 3 \mathrm{~b}$ molecules per particle as described in the Methods. The upper two curves were obtained with $E_{R}$ : $(\square)$, radiolabeled $C 3$ measurements; $(\square)$, ELISA results. The center two curves were obtained with $K$. pneumoniae: $(\bullet)$, radiolabeled $\mathrm{C} 3$ measurements; $(\mathrm{O})$, ELISA results. The lower (base line) curves were obtained with $E_{s}:(\Lambda)$, radiolabeled $C 3$ measurements; $(\Delta)$, ELISA results.

Use of the ELISA to compare the PAP with MgEGTA-NHS as sources of the alternative pathway. $\mathrm{E}_{\mathrm{R}}, K$. pneumoniae, and $\mathrm{E}_{\mathrm{s}}$ were incubated with the PAP and with MgEGTA-NHS. Periodic replicate samples were centrifuged through sucrose and the pellets analyzed by the ELISA. As shown in Fig. 7, the two sources of the alternative pathway exhibited parallel kinetic

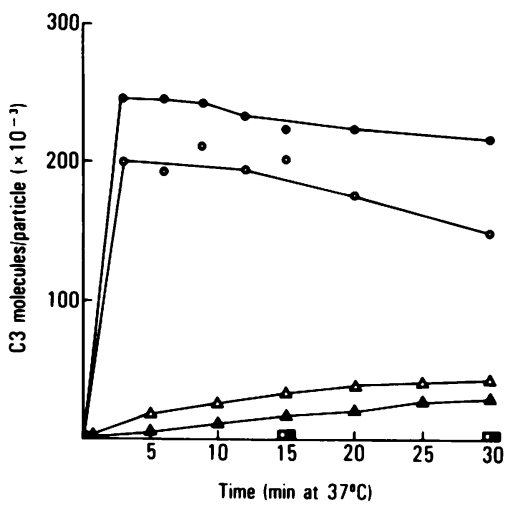

Figure 7. Use of the ELISA to compare MgEGTA-NHS with the PAP. $\mathrm{E}_{\mathrm{R}}, K$. pneumoniae, and $\mathrm{E}_{\mathrm{s}}$ were incubated with MgEGTANHS and with the PAP. Replicate samples were taken at intervals, centrifuged, and the pellets resuspended and assayed in the ELISA The upper two curves were obtained with $E_{R}$ as the activator: $(O)$, MgEGTA-NHS; $(\bullet)$, PAP. The center two curves were obtained with K. pneumoniae: $(\triangle)$, MgEGTA-NHS; ( $\triangle$ ), PAP. The lower (base line) curves were obtained with $E_{s}:(\square)$ MgEGTA-NHS; (घ), PAP. characteristics. The PAP gave somewhat higher values than MgEGTA-NHS with $E_{R}$ as the activator, while this relationship was reversed with $K$. pneumoniae. $\mathrm{E}_{\mathrm{s}}$ were not reactive in the ELISA with either alternative pathway source.

Parameters of the alternative pathway ELISA. Dose-response studies were performed with varying numbers of $E_{R}$ and $K$. pneumoniae. After incubation with a constant amount of MgEGTA-NHS for $10 \mathrm{~min}\left(\mathrm{E}_{\mathrm{R}}\right)$ or $20 \mathrm{~min}$ (K. pneumoniae), the mixtures were diluted and aliquots assayed in the ELISA. As shown in Fig. 8, ELISA reactivity was dose dependent. The effect of different amounts of the activator on the kinetics of the reaction with MgEGTA-NHS was also examined. Several concentrations of $\mathrm{E}_{\mathrm{R}}\left(10^{7}, 10^{8}\right.$, and $\left.10^{9} / \mathrm{ml}\right)$ were incubated with a constant amount of MgEGTA-NHS. Samples that were taken at intervals were diluted and aliquots examined for ELISA reactivity. The family of curves obtained were parallel and showed peak reactivity at $5 \mathrm{~min}$ followed by a gradual decline (not shown).

The stability of the ELISA-reactive complexes generated with alternative pathway activation was examined. MgEGTA-NHS was incubated with zymosan for $1 \mathrm{~h}$ at $37^{\circ} \mathrm{C}$, after which EDTA was added to prevent further activation. Incubation was continued at $37^{\circ} \mathrm{C}$. Samples that were taken at intervals over the next $24 \mathrm{~h}$ were diluted and assayed by the ELISA. At the 1-h time point, $300 \mathrm{ng} / \mathrm{ml}$ of $\mathrm{C} 3 \mathrm{~b}$ were detected by the ELISA. Reactivity declined very slowly with first order kinetics at a rate of $1.25 \% / \mathrm{h}$ over the next $24 \mathrm{~h}$ (not shown). Simultaneous C3 hemolytic measurements were also performed. At the 1-h time point, hemolytically active $\mathrm{C} 3$ in the serum had been depressed to $30 \%$ of the initial value; thereafter, C3 hemolytic activity declined with first order kinetics at a rate of $\sim 2.5 \% / \mathrm{h}$. In similar studies, serum incubated alone for several hours at $37^{\circ} \mathrm{C}$ became reactive in the ELISA. Only a minor proportion of the serum $\mathrm{C} 3(0.007 \%)$ was involved in this spontaneous activation reaction at the time of maximal reactivity $(6 \mathrm{~h})$. After this time, reactivity was lost, with first order kinetics, at a rate of $1.25 \% / \mathrm{h}$. C3 he-

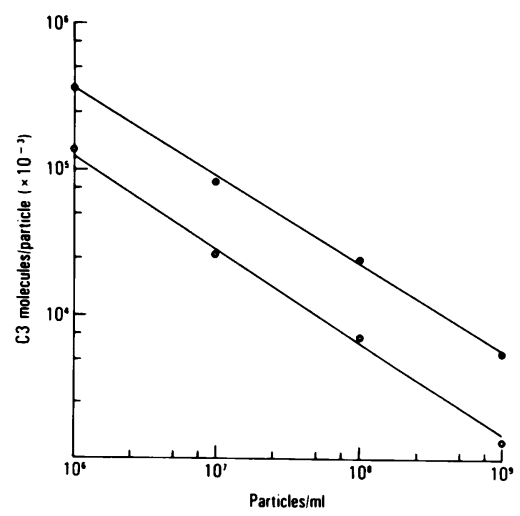

Figure 8. Relationship between activator dose and reactivity in the ELISA. Varying numbers of $E_{R}$ and $K$. pneumoniae were incubated with MgEGTA-NHS. After 10 and $20 \mathrm{~min}$ for $\mathrm{E}_{\mathrm{R}}$ and $K$. pneumoniae respectively, the mixtures were diluted and aliquots tested in the ELISA: $(\bullet), \mathrm{E}_{\mathrm{R}} ;(\mathrm{O}), \mathrm{K}$. pneumoniae. 
molytic function in the spontaneously activated serum was lost with first order kinetics at a rate of $2.5 \% / \mathrm{h}$.

Measurement of activation kinetics with strong, moderate, and weak alternative pathway activators. Activation kinetics were measured with $\mathrm{E}_{\mathrm{R}}, K$. pneumoniae, Raji cells, and $\mathrm{E}_{\mathrm{s}}$. The particles were incubated with MgEGTA-NHS and the mixtures sampled at intervals, diluted, and the aliquots examined in the ELISA. As shown in Fig. 9, $\mathrm{E}_{\mathrm{R}}$ gave peak reactivity at 5-10 $\mathrm{min}, K$. pneumoniae at 15-20 min, and Raji cells at $>30 \mathrm{~min}$. $\mathrm{E}_{\mathrm{s}}$ were not reactive.

Applications and utility of the alternative pathway ELISA. The great sensitivity of the ELISA permits the study of very low levels of alternative pathway activation not readily quantitated by other techniques. For instance, the ELISA can be used to detect alternative pathway activation by particles as small as viruses (Table I). In these studies, Epstein-Barr, Influenza, and Moloney leukemia viruses were incubated either with normal serum or with MgEGTA-NHS. After 20 min at $37^{\circ} \mathrm{C}$, the mixtures were diluted and the aliquots examined in the ELISA. All three viruses activated the alternative pathway as shown by the generation of ELISA reactivity after incubation in MgEGTA-NHS (Table I).

The ELISA can also be used to analyze reaction mechanisms of the alternative pathway. For example, in the present studies, we have observed ELISA reactivity engendered secondary to activation of the classical pathway by some, but not other classical pathway activators. For example, the nonimmune classical pathway activators, Moloney leukemia virus and DNA, triggered the amplification loop with $P$ recruitment as manifested by reactivity in the ELISA after incubation in normal serum (Table I). Classical pathway activation leading to alternative pathway activation with $P$ recruitment could also be demonstrated on adding zymosan and human immune complexes to serum if

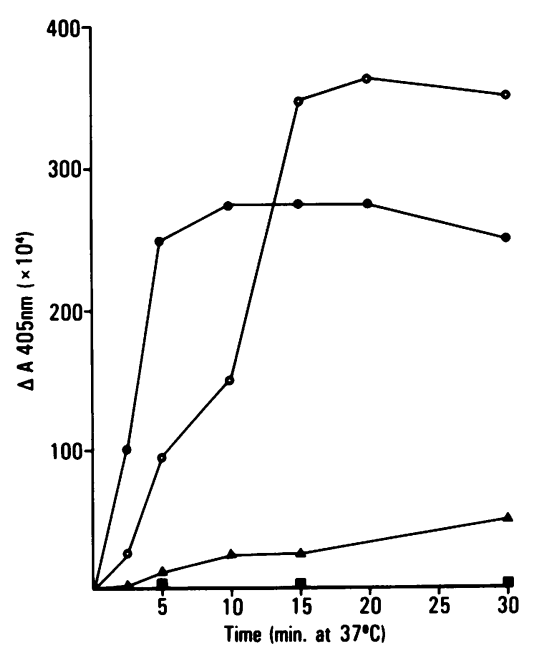

Figure 9. Relationship between activator and time of peak reactivity in the ELISA. $E_{R}, K$. pneumoniae, and Raji cells were incubated with MgEGTA-NHS. Samples were taken at intervals and diluted, and the aliquots were examined in the ELISA: $(\bullet), \mathrm{E}_{\mathrm{R}} ;(\mathrm{O}), \mathrm{K}$. pneumoniae; $(\boldsymbol{\Delta})$, Raji cells, (匹) $\mathrm{E}_{\mathbf{s}}$.
Table I. Reactivity of Various Activators in the Alternative Pathway ELISA

\begin{tabular}{lll}
\hline & \multicolumn{1}{c}{$\Delta \mathrm{A} 405 \mathrm{~nm}\left(\times 10^{4}\right)$} & \\
\cline { 2 - 3 } & & MgEGTA- \\
Activator & $301(1,000)^{*}$ & $142(500)$ \\
\hline Epstein-Barr virus & $100(500)$ & $45(200)$ \\
Influenza WS/33 & 156 & 58 \\
Moloney leukemia virus & 100 & 73 \\
Calf thymus DNA & 193 & 187 \\
Zymosan (1:4 serum) & 124 & 3 \\
Zymosan (1:16 serum) & 100 & 88 \\
Immune complexes (1:4 serum) & 42 & 0 \\
Immune complexes (1:16 serum) & 5 & 7 \\
Heparin & 12 & 10 \\
EA & 8 & 14 \\
EAC4b3b & & \\
\hline
\end{tabular}

* Values in parentheses denote bound C $3 \mathrm{~b}$ molecules/virion.

the serum was first diluted to abrogate reactivity of the alternative pathway (Table I). Other classical pathway activators such as EA, EAC4b3b, and heparin incubated with normal serum failed to recruit the alternative pathway (Table I). Classical pathway reactivity by Moloney leukemia virus, DNA, zymosan, immune complexes, EA, and heparin, was independently verified in these studies.

Detection of alternative pathway activation in clinical sera with the ELISA. The stability of the ELISA reactive complexes permits the ELISA to be used to examine clinical sera. Most of the modest numbers of sera tested from patients with ARDS, typhoid fever, and malaria were positive, with the ARDS patients exhibiting the highest levels (Fig. 10). In contrast, nine sera from patients with $\mathrm{C} 3 \mathrm{NeF}$ were not reactive in the alternative pathway ELISA (Fig. 10). In other studies, 9 of 47 sera from patients with gram-negative sepsis, 6 of 25 sera from patients with acute trauma and shock, and sera from 3 of 29 patients with systemic lupus erythematosus (SLE) also showed elevated values in the alternative pathway ELISA.

\section{Discussion}

This paper describes and validates a new, specific, and highly sensitive ELISA for the detection and quantitation of alternative complement pathway activation in human serum or plasma. Reactivity in the alternative pathway ELISA is dependent on the dual presence of $\mathrm{P}$ and a $\mathrm{C} 3$ derivative on the same activating particle or complex. In most cases, the derivative would be $\mathrm{C} 3 \mathrm{~b}$, but $\mathrm{C} 3$ bi, $\mathrm{P}$ would also be detected. Integrity of the alternative pathway and magnesium were required for ELISA reactivity (Fig. 2-4). In a series of studies to validate the ELISA, $\mathrm{E}_{\mathrm{s}}$ were converted to alternative pathway activators by treatment with neuraminidase (Fig. 5), and the kinetics of alternative pathway 


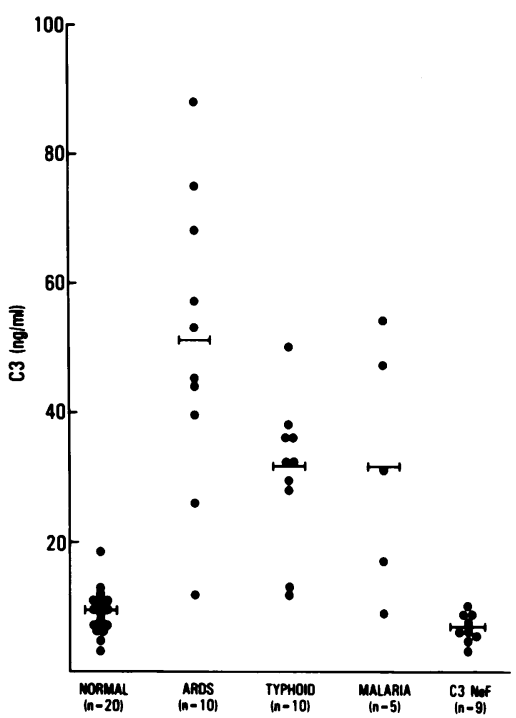

Figure 10. Testing of clinical sera. Serum or plasma samples from patients with diagnoses of ARDS, typhoid fever, or malaria, or containing $\mathrm{C} 3 \mathrm{NeF}$ were diluted and examined in the ELISA. Bars represent the mean value.

activation assessed with the ELISA were identical to those observed in another technique used to measure activation, deposition of radiolabeled C3b (Fig. 6). In other studies, MgEGTANHS and the PAP produced identical activation kinetics with several activators in the ELISA (Fig. 7). Only modest differences in the detected numbers of bound $\mathrm{C} 3 \mathrm{~b}$ molecules were observed. The time of maximal reactivity detected by the ELISA correlated with the strength of the alternative pathway activator as assessed by an independent measure of activation, the restriction index (RI) (42). The RI, which is the ratio of bound Factor $H$ to bound $\mathrm{C} 3 \mathrm{~b}$ molecules, is an inverse measure of activator strength $(42,49,50)$. Thus, a strong activator such as $E_{R}$ with an RI of 0.1 exhibited maximal reactivity in the ELISA after 5-10 min of incubation. Moderate activators, such as E. coli $\mathrm{O} 4, K$. pneumoniae, and neuraminidase-treated $\mathrm{E}_{\mathrm{s}}$ with an RI value of 0.3 showed peak reactivity after 15-30 min of incubation. Weak activators, such as Raji cells with an RI of 0.6 , exhibited maximal activity after $30 \mathrm{~min}$ of incubation while an even longer period of time $(6-8 \mathrm{~h})$ was required for maximal reactivity in the "spontaneous" activation reaction.

Quantitation in the ELISA was achieved by comparing experimental sample values with those obtained with a purified C3 standard curve included on each plate. The numbers of $\mathrm{C} 3 \mathrm{~b}$ molecules detected on activators attached to plates via anti-P, as derived from the standard curve with purified $\mathrm{C} 3$, were very similar to those obtained by measuring deposition of radiolabeled C3 (Fig. 6). This finding validates the C3b ELISA measurements.

The ELISA furnishes a considerable advantage over other alternative pathway tests. It directly measures activation while certain other tests, such as alternative pathway mediated lysis of $E_{R}(51)$, measure not activation but residual functional activity of the pathway. Furthermore, lysis is a secondary event, which is dependent also on the integrity of the membrane attack pathway. Certain other tests either based on measurement of individual protein levels, conversion products, or assessment of the functional integrity of the pathway (52-55) can provide evidence that activation has occurred, but they do not directly measure activation.

The only currently available approach to directly detect and quantitate activation depends on the binding of radiolabeled $P$, C3b, Factor B, Factor H, or combinations thereof to activators $(41,49,55)$. The ELISA is simpler, utilizes fewer particles, and does not require purified functionally active, radiolabeled components. Among the other major advantages of the ELISA is its great sensitivity. For example, $10-20 \mathrm{ng} / \mathrm{ml}$ of C3b deposited together with $\mathrm{P}$ on an activator are readily measurable (Fig. 1). This value corresponds to $\sim 0.0015 \%$ of the $\mathrm{C} 3$ in serum. This sensitivity permits the analysis of minor degrees of alternative pathway activation not previously detectable. Thus, "spontaneous" activation can be quantitated and studied. The sensitivity also allows, for the first time, the study of alternative pathway activation by activators available in only limited amounts, such as viruses (Table I). Great sensitivity is an intrinsic property of enzyme immunoassays and many are comparable to radioimmunoassays in this regard. This is particularly true of the alternative pathway ELISA which uses antibodies to different proteins present in a complex. This gives extreme specificity coupled with negligible background reactivity.

Studies with the ELISA revealed complexities in the reaction mechanism of the alternative pathway which merit further investigation. For example, several activators, including several viruses, DNA, zymosan, and immune complexes, activated the classical pathway leading to secondary triggering of the amplification loop with recruitment of $P$, while other classical pathway activators, such as EA, EAC4b3b, and heparin, did not have this ability. Another example is the rapid appearance of stable ELISA-reactive complexes in the supernatant of mixtures of serum with certain activators, such as zymosan and $K$. pneumoniae, but not with other activators such as $\mathrm{E}_{\mathrm{R}}$. Such complexes could be eluted $\mathrm{C} 3 \mathrm{~b}, \mathrm{P}$ complexes or eluted activated $\mathrm{P}$, which could directly interact with $\mathrm{C} 3 \mathrm{~b}$ in the supernatant $(40,56)$.

A final advantage of the alternative pathway ELISA is that it can detect and quantitate activation which has already occurred, since $P$ and $C 3 b$-bearing complexes are extremely stable in plasma and serum, even when collected and stored under less than optimal conditions. This allows its use with clinical sera (Fig. 10). The ELISA should be readily adaptable to such use. The required antisera are available commercially, and affinity purification of the antisera could be accomplished without isolation of $\mathrm{P}$ and $\mathrm{C} 3$.

Studies with clinical sera showed that some of the sera from patients with typhoid fever and with malaria were moderately reactive in the alternative pathway ELISA while others were not (Fig. 10). Parallel studies of the same samples by using the recently developed classical pathway ELISA (57) showed evidence of marked $\mathrm{Cl}$ activation in all of the typhoid fever samples and in several of the malaria samples. Most of the 10 sera from ARDS patients examined were quite reactive in the alternative 
pathway ELISA (Fig. 10). In contrast, eight of these sera were negative, and two were only marginally reactive in the classical pathway ELISA. A proportion of sera from patients with gramnegative sepsis, trauma, and shock were also reactive in the alternative pathway ELISA. These findings with ARDS, gramnegative sepsis, trauma, and shock are in accord with indications of the involvement of the alternative pathway in these conditions $(2,14-18)$.

26 of the 29 SLE sera examined here were negative in the alternative pathway ELISA. These sera all showed evidence of marked classical pathway activation (greatly reduced total hemolytic complement [CH50] levels), which is a common finding in this disease (58-60). 3 of the 29 SLE sera did react in the alternative pathway ELISA; this confirmed the indications of activation of this pathway in the serum (61-63) and tissues (64, 65 ) of a proportion of patients with SLE. The relative contributions of the classical and alternative pathways to the pathogenesis and symptomatology of this disease are not understood.

Sera from patients with $\mathrm{C} 3 \mathrm{NeF}$ in their circulation were not reactive in the alternative pathway ELISA. Such individuals have very low levels of circulating $\mathrm{C} 3$ due to marked and apparently continuous alternative pathway activation. The sera examined here also had extremely low C3 levels and absent alternative pathway functional activity. However, fluid-phase activation of the alternative pathway by $\mathrm{C} 3 \mathrm{NeF}$ as manifested in clinical sera differs in certain respects from in vitro activation by zymosan, $\mathrm{E}_{\mathrm{R}}$, gram-negative bacteria, and other activators. In particular, Factor B, P, and functional and protein $\mathrm{C} 5$ levels in sera containing $\mathrm{C} 3 \mathrm{NeF}$ are generally normal (66-68). The normal concentrations of Factor $\mathrm{B}$ and $\mathrm{P}$ indicate that there are relatively low levels of $\mathrm{C} 3$ convertase in the circulation of patients with $\mathrm{C} 3 \mathrm{NeF}$. The normal $\mathrm{C} 5$ levels document the absence of a $\mathrm{C} 5$ convertase in the circulation of patients with $\mathrm{C} 3 \mathrm{NeF}$; this is also a relevant observation as there is some evidence that $P$ is recruited and activated by the $C 5$ convertase (C3b)n, $\mathrm{Bb}(69)$. While the explanations for these findings are not immediately apparent, they do account for the failure of such sera to react in the alternative pathway ELISA.

Thus, sera from patients with certain, but not other diseases, are markedly reactive in the alternative pathway ELISA. It will be most interesting to examine sera from patients with a spectrum of diseases in which alternative pathway activation has been demonstrated or suspected to determine whether the test is a diagnostic aid and of value for monitoring clinical status and response to therapy. Since damaged tissues and cells, many gram-negative bacteria, virus-infected cells, and protozoa activate the alternative complement pathway in vitro, a comprehensive examination of sera from patients with burns, major trauma, surgical procedures, septicemia, shock syndromes and in particular septic shock, ARDS, and viral and tropical diseases will be of considerable interest.

\section{Acknowledgments}

We thank Dr. Michael K. Pangburn for helpful discussions. We also thank Ms. Bonnie Weier for preparation of the manuscript.
This work was supported by U. S. Public Health Service grants CA 34120, CA 14692, AI 17354, and HL 07195.

\section{References}

1. Pillemer, L., L. Blum, I. H. Lepow, O. A. Ross, E. W. Todd, and A. C. Wardlaw. 1954. The properdin system and immunity: I. Demonstration and isolation of a new serum protein, properdin, and its role in immune phenomena. Science (Wash. DC). 120:279-285.

2. McCabe, W. B. 1973. Serum complement levels in bacteremia due to gram negative sepsis. $N$. Engl. J. Med. 288:21-23.

3. Winkelstein, J. A., and A. Tomasz. 1978. Activation of the alternative complement pathway by pneumococcal cell wall teichoic acid. J. Immunol. 120:174-178.

4. Wedgwood, R. J., H. S. Ginsburg, and L. Pillemer. 1956. The properdin system and immunity. VI. The inactivation of Newcastle disease virus by the properdin system. J. Exp. Med. 104:707-725.

5. McSharry, J. J., R. J. Pickering, and L. A. Caliguiri. 1981. Activation of the alternative complement pathway by enveloped viruses containing limited amounts of sialic acid. Virology. 114:507-515.

6. Noguema, N. 1975. Studies on selective lysis and purification of trypanosoma cruzi. J. Exp. Med. 142:224-229.

7. Dias da Silva, W., and M. D. Kazatchkine. 1980. Schistosoma mansoni: activation of the alternative pathway of human complement by Schistosomula. Exp. Parasitol. 50:278-286.

8. Macher, A. M., J. E. Bennett, J. R. Gadek, and M. M. Frank. 1978. Complement depletion in cryptococcal sepsis. J. Immunol. 120:1686-1690

9. Jordan, R. E. 1975. Complement activation in bullous skin diseases. J. Invest. Dermatol. 65:162-169.

10. Ziegler, J. B., F. S. Rosen, C. A. Alper, W. Grupe, and I. H. Lepow. 1975. Metabolism of properdin in normal subjects and patients with renal disease. J. Clin. Invest. 56:761-767.

11. Conry, J. M., W. C. Marshall, L. A. Guthrie, A. G. Purkss, and R. B. Johnston. 1981. Deficient activity of the alternative pathway of complement in $\beta$-thalessemia major. Am. J. Dis. Child. 135:529-531.

12. Conry, J. M., R. B. Polhill, S. R. Edmonds, and R. B. Johnston. 1976. Activity of the alternative pathway after splenectomy: comparison to activity in sickle cell disease and hypogammaglobulinemia. J. Pediatr. 95:964-969.

13. Hinz, C. F., Jr., W. S. Jordan, and L. Pillemer. 1956. The properdin system and immunity. IV. The hemolysis of erythrocytes from patients with paroxysmal nocturnal hemaglobulinemia. J. Clin. Invest. 35:453-457.

14. Hammerschmidt, D. E., L. J. Weaver, L. D. Hudson, P. R. Craddock, and H. S. Jacob. 1980. Association of complement activation and elevated plasma C5a with adult respiratory distress syndrome. Lancet. I:947-949.

15. Hosea, S., E. Brown, C. Hammer, and M. Frank. 1980. Role of complement activation in a model of adult respiratory distress syndrome. J. Clin. Invest. 66:375-382.

16. Fearon, D. T., S. Ruddy, P. H. Schur, and W. R. McCabe. 1975. Activation of the properdin pathway in patients with gram negative bacteremia. N. Engl. J. Med. 292:937-940.

17. Nathenson, G., M. E. Muller, K. A. Myers, A. Stitzel, and R. E. Spitzer. 1978. Decreased opsonic and chemotactic activities in sera of post burn patients and partial opsonic restoration with properdin and properdin convertase. Clin. Immunol. and Immunopathol. 9:269276.

18. Bjornson, A. B., H. S. Bjornson, and W. A. Altemeier. 1981. Reduction in alternative complement pathway mediated $\mathrm{C} 3$ conversion following burn injury. Ann. Surg. 194:224-231. 
19. Craddock, P. R., J. Fehr, A. P. Dalmasso, K. L. Brigham, and H. S. Jacob. 1977. Hemodialysis leukopenia. Pulmonary vascular leukostasis resulting from complement activation by dialyzer cellophane membrane. J. Clin. Invest. 59:879-888.

20. Chenoweth, D. E., S. W. Cooper, T. E. Hugli, R. W. Stewart, E. H. Blackstone, and J. W. Kirklin. 1981. Complement activation during cardiopulmonary bypass. N. Engl. J. Med. 304:497-503.

21. Arroyave, C. M., N. H. Bhat, and R. Crown. 1976. Activation of the alternative pathway of the complement system by radiographic contrast media. J. Immunol. 117:1866-1869.

22. Gewurz, H., H. S. Shin, and S. E. Mergenhagen. 1968. Interactions of the complement system with endotoxic lipopolysaccharide consumption of each of the six terminal complement components. $J$. Exp. Med. 128:1049-1057.

23. Smith, T. F., K. McIntosh, M. Fishaut, and P. M. Henson. 1981. Activation of complement by cells infected with respiratory syncytial virus. Infect. Immun. 33:43-48.

24. Cooper, N. R. 1979. Humoral immunity to viruses. In Comprehensive Virology. H. Frankel-Conrat and R. R. Wagner, editors. Plenum Publishing Corp., New York. 123-170.

25. Kierszenbaum, F., and D. Weinman. 1977. Antibody independent activation of the alternative pathway in human serum by parasitic cells. Immunology. 32:245-249.

26. Ratnoff, W. D., J. M. Pepple, and J. A. Winkelstein. 1980. Activation of the alternative complement pathway by histoplasma capsulatum. Infect. Immun. 30:147-149.

27. Heideman, M. 1979. Complement activation in vitro induced by endotoxin and injured tissue. J. Surg. Res. 26:670-673.

28. Hammerschmidt, D. E., C. Greenberg, O. Yamada, P. R. Craddock, and H. S. Jacob. 1981. Cholesterol and atheroma lipids activate complement and stimulate granulocytes. J. Lab. Clin. Med. 98:68-77.

29. Fearon, D. T., and K. F. Austen. 1977. Activation of the alternative complement pathway due to resistance of zymosan bound amplification to endogenous regulatory mechanisms. Proc. Natl. Acad. Sci. USA. 74:1683-1687.

30. Müller-Eberhard, H. J., and R. D. Schreiber. 1980. Molecular biology of the alternative pathway of complement. Adv. Immunol. 29:153.

31. Mayer, M. M. 1967. Experimental Immunochemistry. E. A. Kabat and M. M. Mayer, editors. Charles C. Thomas, Publisher, Springfield, IL 133.

32. Tack, B. F., and J. W. Prahl. 1976. Third component of human complement: purification from plasma and physicochemical characterization. Biochemistry. 15:4513-4521.

33. Götze, O., and H. J. Müller-Eberhard. 1971. The C3 activator system: an alternative pathway of complement activation. J. Exp. Med. 134:905-1085.

34. Götze, O., and H. J. Müller-Eberhard. 1974. The role of properdin in the alternative pathway of complement activation. J. Exp. Med. 139:44-57.

35. Pangburn, M. K., R. D. Schreiber, and H. J. Müller-Eberhard. 1977. Human complement C3b inactivator: isolation, characterization, and demonstration of an absolute requirement for the serum protein B1H for cleavage of C3b and C4b in solution. J. Exp. Med. 146:257270.

36. Pangburn, M. K., R. D. Schreiber, and H. J. Müller-Eberhard. 1981. Formation of the initial C3 convertase of the alternative complement pathway. J. Exp. Med. 154:856-867.

37. Schreiber, R. D., M. K. Pangburn, A. B. Bjornson, M. A. Brothers, and H. J. Müller-Eberhard. 1982. The role of C3 fragments in endocytosis and extracellular cytotoxic reactions by polymorphonuclear leukocytes. Clin. Immunol. and Immunopathol. 23:335-357.
38. Tenner, A. J., P. H. Lesavre, and N. R. Cooper. 1981. Purification and radiolabelling of human Clq. J. Immunol. 127:648-653.

39. Schreiber, R. D., R. G. Medicus, O. Götze, and H. J. MüllerEberhard. 1979. Properdin and nephritic factor dependent $C 3$ convertases: requirement of native $\mathrm{C} 3$ for enzyme formation and the function of bound C3 as properdin receptor. J. Exp. Med. 142:760-772.

40. Medicus, R. G., A. F. Esser, H. N. Fernandez, and H. J. MüllerEberhard. 1980. Native and activated properdin: interconvertibility and identity of amino and carboxy terminal sequences. J. Immunol. 124:602606.

41. Schreiber, R. D., M. K. Pangburn, P. H. Lesavre, and H. J. Müller-Eberhard. 1978. Initiation of the alternative pathway of complement: recognition of activators by bound $\mathrm{C} 3 \mathrm{~b}$ and assembly of the entire pathway from six isolated proteins. Proc. Natl. Acad. Sci. USA. 75:3948-3952.

42. Pangburn, M. K., and H. J. Müller-Eberhard. 1978. Complement C3 convertase: cell surface restriction of BIH control and generation of restriction on neuraminidase treated cells. Proc. Natl. Acad. Sci. USA. 75:2416-2420.

43. Ziccardi, R. J. 1982. A new role for C1-inhibitor in homeostasis: control of activation of the first component of complement. J. Immunol. 128:2505-2508.

44. Lowry, O. H., N. J. Rosenbrough, A. L. Farr, and R. J. Randall. 1951. Protein measurement with the folin phenol reagent. J. Biol. Chem. 193:265-275.

45. Nemerow, G., and N. R. Cooper. 1981. Isolation of EpsteinBarr virus and studies of its neutralization by human IgG and complement. J. Immunol. 127:272-278.

46. Beebe, D. P., R. D. Schreiber, and N. R. Cooper. 1983. Neutralization of influenza virus by normal human serum: mechanism involving antibodies and complement. J. Immunol. 130:1317-1322.

47. Cooper, N. R., F. C. Jensen, R. M. Welsh, and M. B. A. Oldstone. 1976. Lysis of RNA tumor viruses by human serum: direct antibody independent triggering of the classical complement pathway. J. Exp. Med. 144:970-984.

48. Voller, A., D. Bidwell, and A. Bartlett. 1980. Enzyme immunosorbent assay. In Manual of Clinical Immunology. N. R. Rose and H. Friedman, editors. American Society for Microbiology, Wash. DC. 359-371.

49. Pangburn, M. K., D. C. Morrison, R. D. Schreiber, and H. J. Müller-Eberhard. 1980. Activation of the alternative complement pathway: recognition of surface structures by bound C3. J. Immunol. 124:977982.

50. Schreiber, R. D., M. K. Pangburn, R. G. Medicus, and H. J. Müller-Eberhard. 1980. Raji cell injury and subsequent lysis by the purified cytolytic alternative pathway of human complement. Clin. Immunol. and Immunopathol. 15:384-396.

51. Platts-Mills, T. A. E., and K. Ishizaka. 1974. Activation of the alternative pathway and human complement by rabbit cells. J. Immunol. 113:348-357.

52. Lesavre, P. H., T. E. Hugli, A. F. Esser, and H. J. MüllerEberhard. 1979. The alternative pathway $\mathrm{C} 3 / \mathrm{C} 5$ convertase: chemical basis of Factor B activation. J. Immunol. 123:529-534.

53. Polhill, R. B., K. M. Pruitt, and R. B. Johnston. 1978. Kinetic assessment of alternative complement pathway activity in a hemolytic system. J. Immunol. 121:363-370.

54. Fearon, D. T., and K. F. Austen. 1975. Initiation of C3 cleavage in the alternative complement pathway. J. Immunol. 115:1357-1361.

55. Day, N. K., R. D. Schreiber, O. Götze, and H. J. Müller-Eberhard. 1976. Reversible activation of proactivator (Factor B) of the alternative pathway without cleavage of the molecule. Scand. J. Immunol. 5:715720. 
56. Chapitis, J., and I. H. Lepow. 1976. Multiple sedimenting species of properdin in human serum and interaction of purified properdin with the third component of complement. J. Exp. Med. 143:241-257.

57. Harpel, P. C., and N. R. Cooper. 1982. Circulating C1 inactivator $\mathrm{Cls-C} 1 \mathrm{r}$ complexes in plasma: quantitation by an enzyme-linked differential antibody immunosorbent assay. Clin. Res. 30:563A.

58. Zvaiffler, N. J. 1981. Etiology and pathogenesis of systemic lupus erythematosus. In Textbook of Rheumatology. W. N. Kelley, E. D. Harris, S. Ruddy, and C. B. Sledge, editors. W. B. Saunders Co., Philadelphia. 1079-1091.

59. Aguado, M. T., L. H. Perrin, R. Ramirez, P. A. Miescher, and P. H. Lambert. 1980. Evaluation of alternative pathway and factor B haemolytic activities in patients with systemic lupus erythematosus: correlations with the alternative pathway regulatory proteins. Clin. Exp. Immunol. 42:495-505.

60. Lloyd, W., and P. H. Schur. 1981. Complement in systemic lupus erythematosus. Clin. Rheum. Dis. 1:519-523.

61. Arroyave, C. M., M. R. Wilson, and E. M. Tan. 1976. Serum factors activating the alternative complement pathway in autoimmune disease: description of two different factors from patients with systemic lupus erythematosus. J. Immunol. 116:821-826.

62. Sissons, J. G. P., J. Libowitch, N. Amos, and D. K. Peters. 1977. Metabolism of the fifth component of complement and its relation to metabolism of third component in patients with complement activation. J. Clin. Invest. 59:704-715.

63. Perrin, L. H., P. H. Lambert, and P. A. Miescher. 1974. Properdin levels in systemic lupus erythemtosus and membranoproliferative glomerulonephritis. Clin. Exp. Immunol. 16:575-581.

64. Rothfield, N., H. A. Ross, J. O. Minta, and I. H. Lepow. 1972. Glomerular and dermal deposition of properdin in systemic lupus erythematosus. N. Engl. J. Med. 287:681-683.

65. Michael, A. F., N. G. Westberg, A. J. Fish, and R. L. Vernier. 1971. Studies on chronic membrano-proliferative glommerulonephritis with hypocomplementemia. J. Exp. Med. 134:208s-227s.

66. Sissons, J. G. P., R. J. West, J. Fallows, D. G. Williams, B. J. Boucher, N. Amos, and D. K. Peters. 1976. The complement abnormalities of lipodystrophy. N. Engl. J. Med. 294:461-465.

67. McLean, R. H., N. J. Siegel, and M. Kashgarian. 1980. Activation of the classical complement pathway in patients with $\mathrm{C} 3$ nephritic factor. Nephron. 25:57-64.

68. Ipp, M. M., J. O. Minta, and E. W. Gelgand. 1977. Disorders of the complement system in lipodystrophy. Clin. Immunol. \& Immunopathol. 7:281-287.

69. Medicus, R. G., O. Götze, and H. J. Müller-Eberhard. 1976. Alternative pathway of complement: recruitment of precursor properdin by the labile $\mathrm{C} 3 / \mathrm{C} 5$ convertase and the potentiation of the pathway. $J$. Exp. Med. 144:1076-1093. 